\title{
Effects of Cadmium on Embryo Hatchability, Larval Development and Survival of the Olive flounder, Paralichthys olivaceus
}

\author{
Eun Young Min*, Ju-Chan Kang ${ }^{\dagger}$ \\ Department of Aquatic Life Medicine, Pukyong National University, 45, Yongso-ro, Nam-Gu. Busan, Korea \\ *Institute of Fisheries Sciences, Pukyong National University, 474, Ilgwang-ro, Ilgwang-myeon, Gijang-gun, Busan, Korea
}

The cadmium (Cd) toxicological effects on the fertilized eggs, embryos and larvae were investigated in olive flounder, Paralichthys olivaceus water-borne exposed to $\mathrm{Cd}$. The survival rate and hatching success of the embryos significantly diminished in treated groups in dependence of the $\mathrm{Cd}$ concentration. Significant differences were found at $\geq 30 \mu \mathrm{g} \mathrm{L}^{-1}$ exposed groups compared to the control group. A significant increase of malformation of the embryo was observed at $\geq 20 \mu \mathrm{g} \mathrm{L}^{-1}$ exposed groups. They usually include such symptoms as clouded yolk-sac abnormality, fin erosion and spinal curvature. A significant reduction in the survival rate of the larvae was observed in $\geq 20 \mu \mathrm{g}$ $\mathrm{L}^{-1}$ exposed groups with accompanied by the disorder. Notably, in larvae, a concentration as low as $10 \mu \mathrm{g} \mathrm{L}^{-1}$ exposed groups caused significant elevated abnormalities that is incidences of spinal cord deformation, abnormal eyes, deformation of the head region and severe developmental delay.

Key words : Cadmium, Olive flounder, Embryo-toxicity

Cadmium (Cd) is highly toxic to early life stages of fish resulting in the alteration of egg size, increased embryo mortality, decrease of hatchability, hatching of smaller larvae and reduced larval growth (Lein et al., 1997). Cd exposure has resulted in morphological embryo deformities, decrease pigmentation and teratogenic effects in several fish species (Fraysse et al., 2006). The early life cycle toxicity test is considered by most aquatic toxicologists to be ultimate test in risk assessment. Embryonic period begins with fertilization or union of the gamete and is characterized by an endogenous food source or yolk. The period ends at hatching. Laval period begins with hatching of the eggs and lasts until the

†Corresponding author: Ju-Chan Kang

TEL : +82-51-620-6146, FAX : +82-51-628-7430

E-mail : jckang@pknu.ac.kr disappearance of a full complement of fin-rays and spines. This period is divided into two phases; the yolk-sac larva or alevin period, which begins at hatching and ends after complete absorption of the yolk with the juvenile.

The main purpose of the present study was to investigate the effects of sub-lethal $\mathrm{Cd}$ exposure on survival, hatching, embryo deformities and survival of larvae in the olive flounder. Generally previous studies have investigated the eco-toxicological responses of fish from a single location (Hallare et al., 2005). Such studies cannot account for geographical patterns of adaptation. In Korea, different fish stocks are used in aquaculture facilities and the present study compared the sensitivity of embryos and larvae derived from fish that originated from three regions with varied environmental anthropogenic inputs. 


\section{Materials and Methods}

Fertilized eggs of olive flounder, Paralichthys olivaceus were obtained from hatcheries in Cheju Island, Yeosu and Chungnam, South Korea. All experiments were done at $20 \pm 0.5{ }^{\circ} \mathrm{C}$ under a $12 \mathrm{hr}$ light/ $12 \mathrm{hr}$ dark cycle using seawater. Five $\mathrm{Cd}$ experimental solutions $\left(5,10,20,30\right.$ and $\left.40 \mu \mathrm{g} \mathrm{L}^{-1}\right)$ were prepared by diluting a stock solution made up in seawater that had been filtered through $\mathrm{GF} / \mathrm{C}$, Whatman filter and UV treated. The eggs obtained from each region were around $7 \mathrm{hr}$ post-fertilization the fertilized eggs (blastula stage) and were transferred directly into $\mathrm{Cd}$ experimental solutions in $500 \mathrm{ml}$ glass beakers. For each $\mathrm{Cd}$ experimental solutions and the control group there were 3 replicates, each containing 50 embryos. The development of the embryos was monitored every $3 \mathrm{hr}$ up to an endpoint of $40 \mathrm{hr}$ or until hatching was complete. At each time interval, embryo mortality, hatching success and any abnormalities were noted using a microscope connected to a camera device $(\times 400)$. Embryos were considered dead when any part of the embryo turned opaque or white. Preliminary experiments had identified potential malformations in the embryo after $\mathrm{Cd}$ exposure as, an irregular egg membrane, atrophy of yolk sac and abnormal tail flexure.

Newly-hatched larvae were exposed to the same $\mathrm{Cd}$ concentration groups and control group as in the embryo toxicity test. The larvae were monitored every $6 \mathrm{hr}$ for up to $72 \mathrm{hr}$ after the time of fertilization. Larvae were considered dead when there was no visible heart beat or body movement. The survival rate was recorded through out the experiment and deformations were quantified at the end of the experiment. The physical abnormalities included yolk sac edema or deformation, erosion of the fins, spinal cord curvature and abnormal tail flexure. The $\%$ data log transformed to normalize the data and treatment groups or locations compared using one-way or two-way analysis of variance (ANOVA). When the ANOVA was significant $(P<0.05)$ this was followed by Dunnett's test to identify the means that were similar.

\section{Results and Discussion}

In control group and in each $\mathrm{Cd}$ concentration group, the survival of embryos collected from the three sites was similar. Survival was above $90 \%$ in the control group and in the 5 and $10 \mu \mathrm{g} \mathrm{L}^{-1}$ exposed groups and significantly lower at 30 and $40 \mu \mathrm{g} \mathrm{L}^{-1}$ exposed groups. The combined results from the three sites described a linear relationship between embryo survival and $\mathrm{Cd}$ concentration (Fig. 1) and the predicted concentration for $50 \%$ mortality would be approximately $43 \mu \mathrm{g} \mathrm{\textrm {L } ^ { - 1 }}$. The results from present study confirm that early life stages of the olive flounder, $P$. olivaceus are sensitive to low concentrations of $\mathrm{Cd}$, reducing the survival of embryos and larvae and negatively affecting their development (Fig. 1 and 6). However, the responses were generally similar in fish raised from stock cultures from different areas in Korea.

This lack of variability between populations may reflect the migratory patterns and wide spread distribution of this species. In white sucker, Catostomus commersoni embryos, $100 \mu \mathrm{g} \mathrm{L} \mathrm{L}^{-1}$ exposed group caused $100 \%$ mortality (Eaton et al., 1978) and in the carp, 


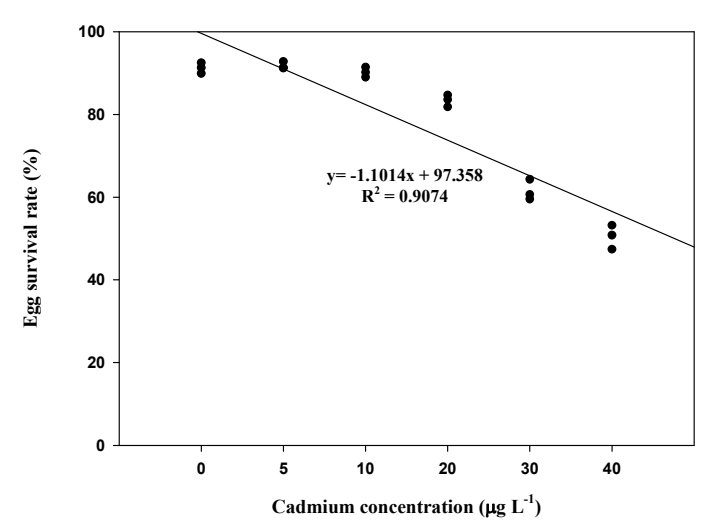

Figure 1. Linear relationship between egg survival rate and Cadmium concentration in the Paralichthys olivaceus collected from sampling sites exposed to various $\mathrm{Cd}$ concentrations.

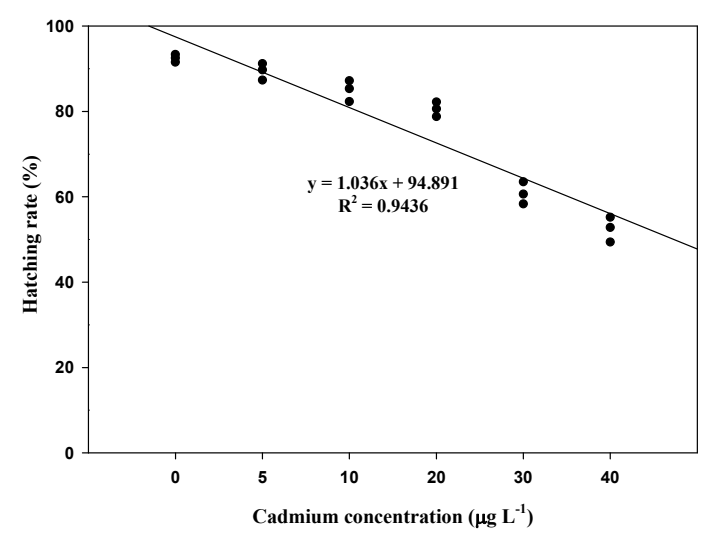

Figure 2. Linear relationship between hatching rate and $\mathrm{Cd}$ concentration in the Paralichthys olivaceus collected from sampling sites exposed to various $\mathrm{Cd}$ concentrations.

Cyprinus carpio, $10 \mu \mathrm{g} \mathrm{\textrm {L } ^ { - 1 }}$ exposed group caused significant $76 \%$ mortality of embryos (Malgorzata et al., 1995). In the present study, P. olivaceus embryos exposed to concentration above $30 \mu \mathrm{g} \mathrm{L}^{-1}$ was significantly reduced survival. This result is consistent with Tak and $\mathrm{Kim}$ (2000) who found $\mathrm{LC}_{50}$ value for water-borne $\mathrm{Cd}$ was $29 \mu \mathrm{g} \mathrm{\textrm {L } ^ { - 1 }}$ for the embryo stage of this species. These values suggest that the embryos of the seawater $P$. olivaceus are less sensitive to $\mathrm{Cd}$ exposure than the eggs of some freshwater species.

Embryo of 10hr post-fertilization in the control group is normal (3A). However, Cd treated embryos observed developmental deviations included blastoderm covering about $1 / 2$ of the yolk sphere, with the oil-droplet being located towards the periphery (Fig. 3C). Remarkably, $\mathrm{Cd}$ treated embryos were appeared to accumulate $\mathrm{Cd}$ in the outer layer of embryos resulting in the appearance of an irregular egg membrane (Fig. 3B and D). After $15 \mathrm{hr}$ post-fertilization, embryos of control group were developed normally with the usual optic cup development (Fig. 4A). In contrast, Cd treated embryos had no or abnormal optic cup formation (Fig. 4B), after $30 \mathrm{hr}$ post-fertilization, skin melano-phores and an eye lens appeared in embryos of control group (Fig. 4C), but these were absent in the $\mathrm{Cd}$ treatments. Other

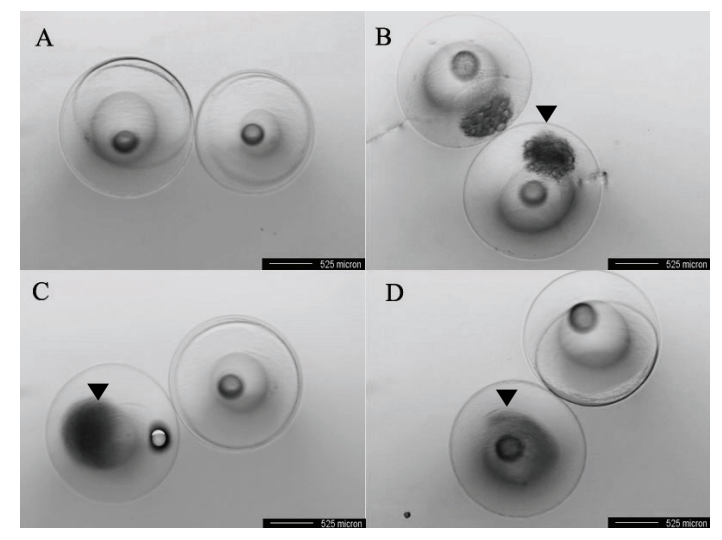

Figure 3. Paralithys olivaceus. Eggs of 10hr post-fertilization in the control group (A) and $40 \mu \mathrm{g} \mathrm{L^{-1 }} \mathrm{Cd}$ treated group (B, C and D). A: Eggs of control group (normal). B: Egg showing that the strange material is on outer layer and irregular egg membrane. C: Darkening of the egg always progress to death. Oil droplet is located at the periphery. D: Egg showing darkened outer layer of all groups. The black arrows point out the abnormalities of eggs exposed to $\mathrm{Cd}$. 


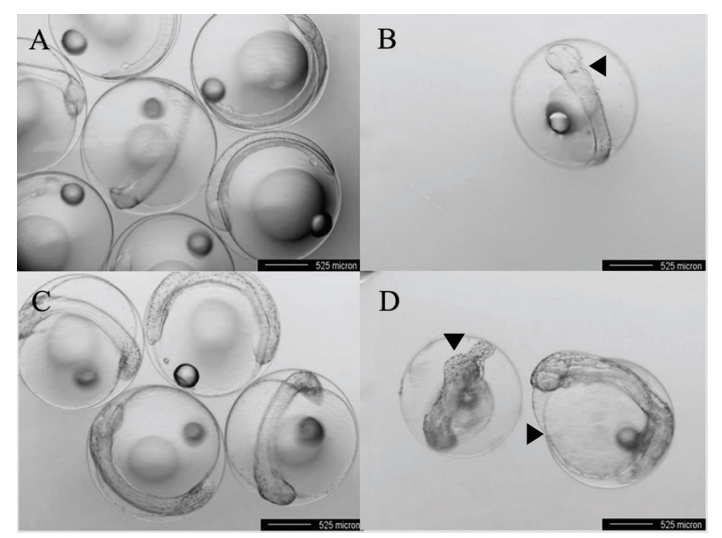

Figure 4. Paralithys olivaceus. Embryos of $15 \mathrm{hr}$ post-fertilization in the control group (A) and $40 \mu \mathrm{g} \mathrm{L}^{-1}$ Cd treated group (B). A: Embryos of control group (normal). B: Abnormal formation of flatted body embryo that its line is not straight, a bumpy line. Embryos of $30 \mathrm{hr}$ post-fertilization in the control group (C) and $40 \mu \mathrm{g} \mathrm{L}^{-1}$ $\mathrm{Cd}$ treated group (D). C: Embryos of control group (normal). D: Embryos undeveloped tail, morphologically irregular yolk. The black arrows point out the abnormalities of embryos exposed to $\mathrm{Cd}$.

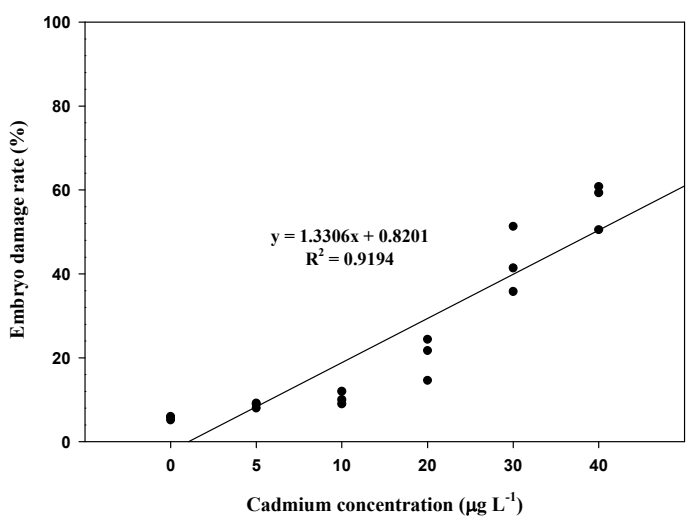

Figure 5. Linear relationship between embryo damage rate and $\mathrm{Cd}$ concentration in the P.olivaceus collected from sampling sites exposed to various $\mathrm{Cd}$ concentrations.

apparent defects resulting from $\mathrm{Cd}$ exposure were abnormal tail flexures and morphological irregular yolk-sac or atrophy (Fig. 4D). There was no significant difference in the $\%$ damage from embryos collected from the three sites $(P<0.05)$ (Fig. 5). The \% embryo damage increased linearly with $\mathrm{Cd}$ concentration (Fig. 5) and the critical $\mathrm{Cd}$ concentration resulting in 50\% embryo damage was $38 \mu \mathrm{g} \mathrm{L}^{-1}$. At Cd concentration of $30 \mu \mathrm{g}$ $\mathrm{L}^{-1}$ there was damage to between of $35 \sim 51 \%$ of embryos, a result which was similar to the $47 \%$ carp, Cyprinus carpio (Malgorzata et al., 1995). Unlike the survival rate, the malformation rate in $P$. olivaceus embryo was similar to freshwater species such as a carp, C. carpio. The most common morphological defect observed in P. olivaceus embryos in this study following $\mathrm{Cd}$ exposure was edema (or atrophy). However, this has also been found in response to other in inorganic or organic pollutants, and is characterized by leakiness of endothelial vessels supplying the yolk-sac, as a result of cardio-vascular dysfunction (Guiney et al., 1990).

The hatching rate for embryos from the three locations was generally similar, especially in the control group and $\mathrm{Cd}$ treated groups of $20 \mu \mathrm{g} \mathrm{L}^{-1}$ or less (Fig. 2). The combined results, calculated from the mean values showed a linear relationship with hatching rate significantly reduced with increasing $\mathrm{Cd}$ concentration $(P<0.05)$ (Fig. 2).

In larvae, survival significantly decreased with increasing $\mathrm{Cd}$ concentration (Fig. 6) and the $\mathrm{LC}_{50}$ value calculated as $25 \mu \mathrm{g} \mathrm{L} \mathrm{L}^{-1}(P<0.05)$. The \% larvae displaying developmental defects was similar in embryos collected from the three collecting areas (Fig. 7). No larval abnormalities were observed in the control group and the $5 \mu \mathrm{g} \mathrm{L}^{-1}$ exposed group. The \% larval abnormalities increased directly with $\mathrm{Cd}$ concentration (Fig. 7). The $\mathrm{Cd}$ concentration resulting in $50 \%$ larval defects was $28 \mu \mathrm{g} \mathrm{L}^{-1}$. For larvae exposed to $10 \mu \mathrm{g} \mathrm{L}^{-1}$ group 


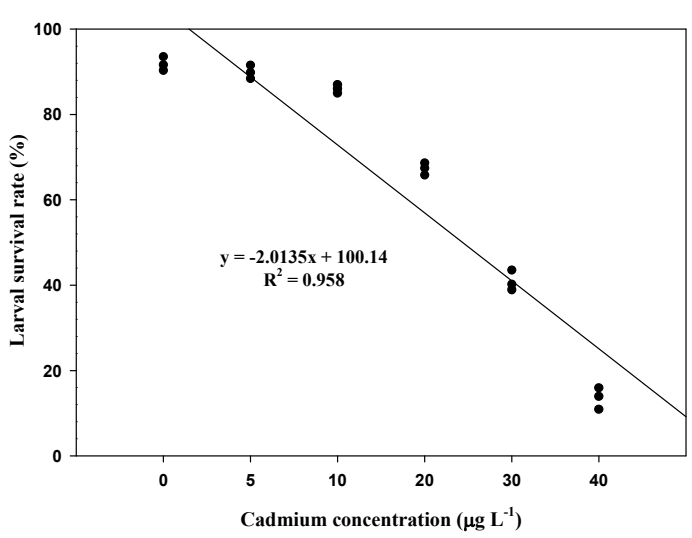

Figure 6. Linear relationship between larval survival rate and $\mathrm{Cd}$ concentration in the $P$. olivaceus collected from sampling sites exposed to various $\mathrm{Cd}$ concentrations.

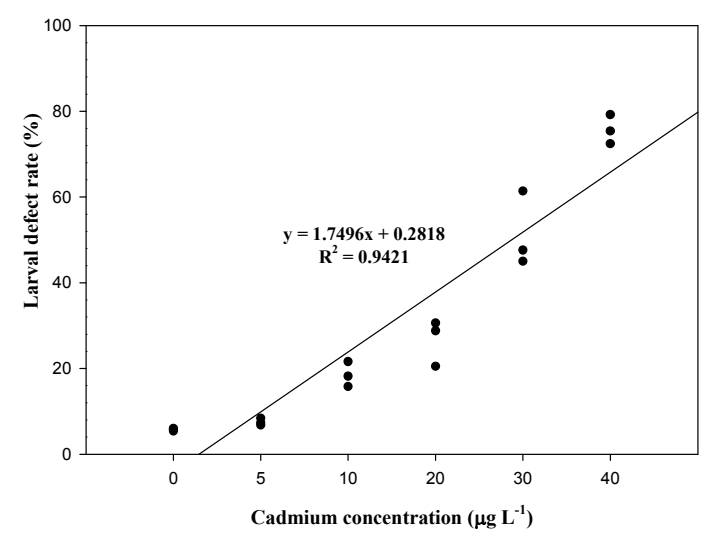

Figure 7. Linear relationship between larval defect rate and Cd concentration in the $P$. olivaceus collected from sampling sites exposed to various $\mathrm{Cd}$ concentrations.

approximately $22 \%$ exhibited lateral curvature or spinal cord deformation (Fig. 8B, C and D for 24hr larvae). Many of the surviving larvae displayed abnormal tail flection and this became more pronounced with increased exposure time (Fig. 9 for $48 \mathrm{hr}$ larvae). In all $\mathrm{Cd}$ treated groups there was dorsal, ventral and caudal fin corrosion, vertebral deformity and abnormality of the yolk-sac (Fig. 9B and C).

The present study confirms that as, in other fish species, $\mathrm{Cd}$ is highly toxic to the larvae of the $P$. olivaceus. The $72 \mathrm{hr}-\mathrm{LC}_{50}$ was $25 \mu \mathrm{g} \mathrm{L}^{-1}$ which is similar

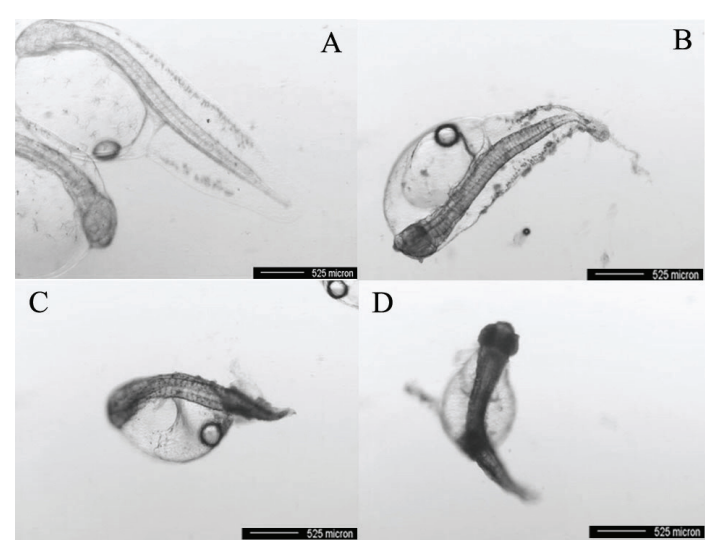

Figure 8. Paralithys olivaceus. Larvae of $36 \mathrm{hr}$ post-hatching in the control group (A) and $40 \mu \mathrm{g} \mathrm{L}^{-1} \mathrm{Cd}$ treated group (B, C, D). A: Larva of control group (normal). B: Larvae showing tail abnormality and dorsal and ventral fin corrosion and darkened head. C: Larvae showing uneveness and atrophy of the yolk. D: Larvae showing spinal deformity, abnormal head and darkening of body. These abnormal larvae observed in all $\mathrm{Cd}$ treated groups.

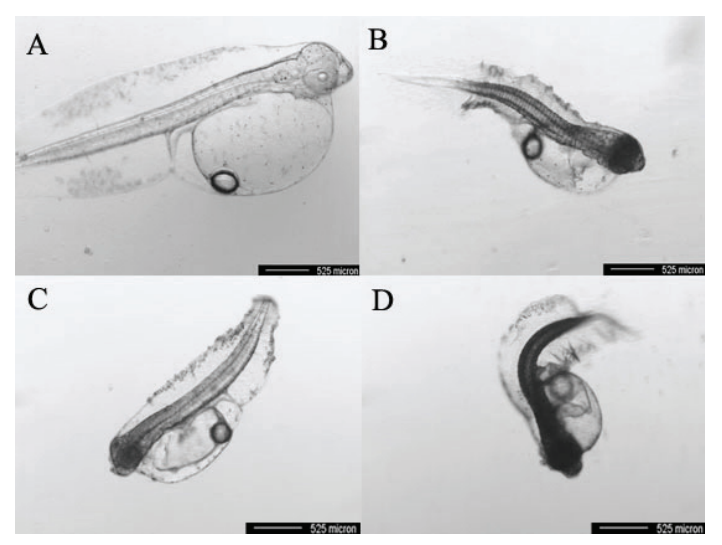

Figure 9. Paralithys olivaceus. Larvae of $60 \mathrm{hr}$ post-hatching in the control group (A) and $40 \mu \mathrm{g} \mathrm{L}^{-1} \mathrm{Cd}$ treated group (B, C, D). A: Larva of control group (normal). B: Larvae showing abnormal yolk atrophy. C: Larvae showing small head and darkened eye, underdeveloped and abnormal development of intestine. D: Stunted development; the spine is extremely curved and complete caudal fin corrosion. These abnormal larvae observed in all $\mathrm{Cd}$ treated groups. 
to a value of $15 \mu \mathrm{g} \mathrm{L}^{-1}$ recorded for the same species by Tak and Kim (2000). For the embryo-larval stage of bull trout, Salvelinus confluentus, exposure to 0.786 $\mu \mathrm{g} \mathrm{L}^{-1}$ resulted in significant accumulation and growth reduction (Hansen et al., 2000). This response is similar to other fish, for example, Christy et al. (2002) found that $5 \mu \mathrm{g} \mathrm{L} \mathrm{L}^{-1}$ exposed group resulted in a significant reduction of the hatching rates of medaka, Oryzias latipes embryos. In the present study, we confirmed that the embryos of $P$. olivaceus were more tolerant of exposure to $\mathrm{Cd}$ than the larvae and those malformations in the different $\mathrm{Cd}$ concentration were higher in the larvae than embryos. These results support a protective role of the egg membrane to water-borne Cd (Noor et al., 1986). The Cd-induced damage in the vertebral column of the carp, C. carpio may be related to depletion of calcium and phosphate (Muramoto, 1985) and in rainbow trout, Oncorhynchus mykiss, Cd may delay organo-genesis through metal induced endocrine disruption (Jones et al., 1978). Williams and Holdway (2000) also reported dose dependent deformities in embryos and larvae of the Australian crimson spotted rainbow fish, Melanotaenia fluviatilis exposed to $2 \mathrm{hr}$ pulses of $\mathrm{Cd}$ $3.3 \mathrm{mg} \mathrm{L}^{-1}$. Similar spinal deformations have also been reported in natural populations of gobies and sands melt from the Adriatic (Lein et al., 1997). While this may also be the case for the olive flounder, the results from the present study suggest that all three sub-populations are equally susceptible and respond in a similar way to low doses of $\mathrm{Cd}$ exposure. The study has highlighted the potential susceptibility of the larval stage compared with the embryo stage and stresses the importance of maintaining good water quality during production. The research also demonstrates that the larval stage of the olive flounder would be a good indicator for $\mathrm{Cd}$ contamination in coastal water and that the responses recorded here may be typical for other contaminants (Fraysse et al., 2006). Finally, exposure to $\mathrm{Cd}$ concentration as low as $10 \mu \mathrm{g} \mathrm{L}^{-1}$ disrupted the development of the early-stage olive flounder, $P$. olivaceus with higher toxicity in larvae than eggs. This study therefore highlights the importance of testing different life stages and recording arrange of end points when assessing the potential effects of contaminants on fish populations.

\section{References}

Christy, M.F., Bethany, N.P., William, H.B.: Influence of parental and developmental cadmium exposure on endocrine and reproductive function in Japanase medaka (Oryzias latipes). Com. Biochem. Physiol., C, 133:345-354, 2002.

Eaton, J.G., Mckim, J.M., Holcombre, G.W.: Metal toxicity to embryos and larvae of seven freshwater fish species. I. Cadmium. Bull. Environ. Contam. Toxicol., 19:95-103, 1978.

Fraysse, B., Mons, R., Garric, J.: Development of a zebrafish 4-day embryo-larval bioassay to assess toxicity of chemicals. Ecotoxicol. Environ. Saf., 63(2):253-267, 2006.

Guiney, P.D., Walker, M.K., Peterson, R.E.: The edema in TCDD-exposed lake trout sac fry is an ultrafiltrate of blood. Abstracts. Soc. Environ. Toxicol. Chem., In Meeting, Arlington, VA, November, pp.11-15, 96, USA, 1990. 
Hallare, A.V.M., Schirling, T., Luckenbach, H., Kohler, R., Triebskom, R.: Combined effects of temperature and cadmium on developmental parameters and biomaker responses in zebrafish (Danio rerio) embryos. J. Thermal. Biol., 30(1):7-17, 2005.

Hansen, J.A., Welsh, P.G., Lipton, J., Cacela, D., Dailey, A.D.: The relative sensitivity bull trout (Salvelinus confluentus) and rainbow trout (Oncorhynchus mykiss) to acute exposure of $\mathrm{Cd}$ and zinc. Environ. Toxicol. Chem., 67(1):67-75, 2002.

Jones, P.W., Martin, F.D., Hardy, J.D.: Development of fishes of the mid-Atlantic bight, An atlas of egg, larval and juvenile stages. Biol. Serv. Prog. vol. 1, USDept Inter Pub., 1FWS/OBS-78/12, 1978. Lein, N.T.H., Adriaens, D., Janssen, C.R.: Morphological abnormalities in African catfish (Clarias gariepinus) larvae exposed to malathion. Chemosphere, 35: 1475-1486, 1997.

Malgorzata, W., Barbara, J., Jerzy, C.: The influence of cadmium on common carp embryos and larvae.
Aquaculture, 129:129-132, 1995.

Muramoto, S.: Vertebral column damage and decrease of calcium concentration in fish exposed experimentally to Cd. Environ. Poll., A, 24:125, 1985.

Noor, A., Shalizi, M., Pascoe, D.: Variable sensitivity of rainbow trout (Salmo gairdneri) eggs and alevins to heavy metals. Bull. Environ. Contam. Toxicol., 36:468-474, 1986.

Tak, K.T., Kim, J.K.: The effect of acute toxicity of marine toxicants on early life of coastal olive flounder. Kor. J. Life Sci., 10(3):247-253, 2000.

Williams, N.D., Holdway, D.A.: The effects of pulse-exposed cadmium and zinc on embryo hatchability, larval development, and survival of Australian crimson spotted rainbow fish (Melanotaenia fluviatilis). Environ. Toxicol., 15(3):165-173, 2000.

Manuscript Received : October 17, 2012
Revised : April 5, 2013
Accepted : April 8, 2013

